\title{
Understanding the Mechanism of Social Media to Promote Green Initiative for Library Sustainability
}

\author{
Tengku Adil Tengku Izhar \\ Universiti Teknologi, Malaysia
}

\begin{abstract}
Social media is a platform to facilitate libraries and their users. The challenge is to use social media for green companies by giving the value to the consumer in the comparison of products and services The aim of this paper is to review previous study that underpins a seamless integration of library green initiative using social media.In order to achieve this aim, we tackle the literature to incorporate social media and library green initiative. The results can lead to some new evaluation methods in green technology from library perspective. The outcome will offer an enormous opportunity to advance the science of data analytics so that future researchers will have a new understanding on what is needed to use social media as a tool to improve library sustainability. The conduct of this survey will ensure the projects agility in responding to unfolding events, and substantially enhance its ability to engage in and impact on green technology and societies.
\end{abstract}

\section{Introduction}

Big data provides significant opportunities for enterprises to impact a wide range of business processes in organizations [1-4]. Although there are many studies conducted on big data in the context of the organizations [2, 5-7], there is still little debate these days on the role and importance of big data for efficient decision-making toward organizational green initiative [7-9]. For many years, the international community has approached environment and development challenges through the lens of sustainable development, which usually conceived as meeting the needs of the current generation while not sacrificing the ability of future generations to meet their own needs [10]. Many organizations are adopting "green" initiatives in order to meet public demand and to draw positive market attention and results. While these different types of green strategic initiatives can be categorized using a competing values framework, there is more controversy over how to operationalize these strategies [11].

Big data platform such as social media is fast becoming a regular part of our everyday lives. Its online communities carry a strong and influential voice, and there is much to be gained from engaging directly with people through these channels, whether for networking, promote a product or service, or just stay up to date with the latest news. Many initiatives have been developed in management, i.e. employee recruitment phase, since the marketing's adoption on social media analysis. However, rarely has social media analysis been included in the context of performance measurement [12].

Social media has the potential to facilitate much closer relationship between libraries and their users. Current usage of social media by the library community generally remains ad hoc and somewhat experimental but they likely play an important role in library service provision and outreach the future. Social media presents a good number of opportunities for libraries, but also many challenges

There is limited differentiation in how social media channels are used to promote green technology. Similar objectives and tactics apply across all social media tools, but it is envisaged that this will change rapidly with strategies becoming increasingly channel-specific. Social media can provide many useful benefits to the individual or organization growing and evolving its sustainable green identity and actions. In a positive, supportive spirit of sustainability and green initiatives, the following ideas are offered to ensure that the use of social media is increasingly successful and useful, in that, it contributes to strategic innovation and management including planning, implementation, and control [11]. Social media can be used for green companies by giving the value to the consumer in the comparison of products and services [13, 14].

The aim of this paper is to review previous study that underpins a seamless integration of library green initiative using social media. In order to achieve this purpose, we investigate various associated concepts and organize the literature based on the library, social media and green technology initiative in the library. The contribution of this survey may serve as a first step in understanding the relationship for library green initiative and social media in relation to the library sustainability. In this paper, all related and relevant primary, secondary and tertiary sources are referred.

The remainder of this paper is organized as follows. Section 2 discusses on big data and the challenges in managing big data. Section 3 discusses on green initiative in the library. Section 4 discusses on library in social media perspective. Section 5 discusses on library green initiative. The final section contains the concluding remarks. 


\section{Big data}

Organizations can create huge volume of data in their daily business activities. The problem though is that, this data was created and captured in many different formats which make it almost impossible to understand the existing relationships between different data. As a result, this huge volume of data may get redundant and hard to identify which data is relevant to the organization's goals. Big Data may be created in petabytes or exabytes scale and much of which cannot be integrated easily. For example, the government agencies, the large, medium and small private enterprises in many domains such as engineering, education, manufacturing, are drowning in an ever-increasing deluge of data. Companies like Google, eBay, LinkedIn, and Facebook were built around Big Data from the beginning [8].

Even though data scientists were trained to analyze data, but with the huge volume of data generated everyday makes it harder to identify which data is relevant to the organization's specific activity. As a result, it poses an issue on how to effectively utilize this data to support decision-making processes [1].

Big data will be important to business organizations because more data can create more accurate analysis which can in turn lead to more confident decision-making. Taking advantage of Big Data opportunities is a challenge for organizations [2]. In order to ensure the effectiveness of the data, organizations need to store the data reliably across a number of databases. Once the data is distributed, and when the needs arise, the organization must find a way to extract the data again, identify which data is needed, assemble it and analyze it. The challenge now is how to capture relevant data from this massive amount of data which can deliver values to the organization's specific activities. Here, the real issue is not how the organizations will acquire the huge volume of data, but how they can harness the value of this data that counts [8].

\subsection{Managing Big Data}

In the past couple of years, we have seen a significant increase in the use of big data analytics that bring data under management [19]. Big data provides significant opportunities for enterprises to impact a wide range of business processes in the organizations. Organizations create huge amount of data in their daily business activities.

The problem is this data is created and found in many different forms such as databases, paper based document, mobile applications, various websites and social media. All these data captures in different formats and makes it almost impossible to understand the existing relationship between different data. The size and complexity of data make it difficult for companies to unlock the true value of their data. In fact, some data is so far out of date that it does not belong in active data storage at all. A key challenge in current environment is determining how to identify data that still relevant for information professionals who receive output of analysis based on this data. Unfortunately, this data cannot be treated disparate information. As a result, this data might be redundant with huge volume of data and make it hard to analyse relevant data into information. Organizations need to use this collection of data and create meaningful information and gain knowledge out of it.

High structure and high quality of data is vital. It is the foundation for organizations to analyse relevant data into information in formal reports and dashboards. This information has to be used to make actions and decisions based on actual facts. This stage is known as information spectrum and it is important to apply this stage across the organizations in the consistent action. Therefore, the entire organization can benefit.

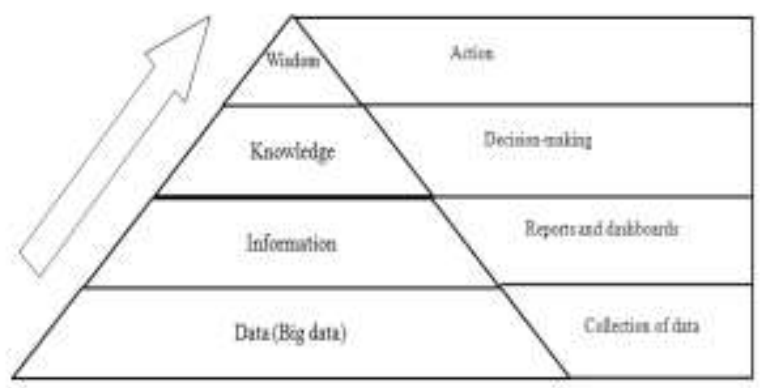

Figure 1. Big data and information management

The implementation of big data highlights the development of big data analytics. Big data analytics could be used to examine large amounts of data from variety of types to discover useful information. Such information can provide a competitive advantage for better decisions. The primary goal of big data analytics is to help companies make better business decisions by enabling data analysts to analyze huge volumes of transaction data, which remains an unresolved challenge for conventional business intelligence programs.

Big data analytics can be done with the software tools commonly used as part of advanced analytics disciplines such as predictive analytics and data mining but the unstructured data sources used for big data analytics may not fit in traditional data warehouses. Furthermore, traditional data warehouses may not be able to handle the processing demands posed by big data. As a result, a new class of big data technology has emerged and is being used in many big data analytics environments. For example, the technologies associated with big data analytics include Hadoop, MapReduce and 
Hortonworks. These technologies form the core of an open source software framework that supports the processing of large datasets across clustered system.

Big data is a rather vague term that describes the application of new tools and techniques to digital information on a size and scale well beyond what was possible with traditional approaches [20]. Big data are typically involving datasets that are so large and complex that they require advanced data storage, management, analysis, and visualization technologies [21, 22].

Recently, Polato et al. [23] studied on the valuable knowledge that can be retrieved from petabyte scale datasets that led to the development of solutions to process information based on parallel and distributed computing. The authors developed a model-based computer to process information from large datasets. Organizations need to understand the flow of their data in order to process it into valuable information. Data flow is an ordered sequence which is consecutive, high-speed, infinite and time varying. For example, it's a great importance in internet management, internet security and internet experiment. However, with the rapid development of internet technology, the number of internet applications in organizations keeps rising, and the data is growing exponentially which make it hard to manage [24].

Esposito et al. [25] studied on big data analytics. The authors focused on an imperative aspect to increase the operating margin of both public and private enterprises. The paper represents the next frontier for their innovation, competition, and productivity in big data era. Big data are typically produced in different sectors, often geographically distributed throughout the world, and are characterized by a large size and variety.

Based on the above discussion, we can see that most of the studies focused on big data process from large amount of datasets. The studies focused on big data creation [21, 22], big data analytic [25], computing approach [23], internet data [24] and big data tools [20].

Table 1. Summary of previous study on big data

\begin{tabular}{|c|c|c|c|c|c|}
\hline Auntans & Cretation & Astabuics & Jools & Oranizaticas & Giten Libray \\
\hline Espssito et al. [23] & & 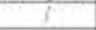 & & 1 & $x$ \\
\hline Potaso ef all [21] & & & 1 & 7 & $x$ \\
\hline Lat 201 & & & 7 & 1 & $x$ \\
\hline Cone 21$]$ & 7 & & & 1 & $\pi$ \\
\hline Penotas [22] & $T$ & & & 1 & 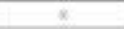 \\
\hline
\end{tabular}

\subsection{Social Media}

The use of social media technologies, such as blogs, wikis, social networking sites, social tagging, and micro-blogging is proliferating at an incredible pace to promote green initiative [43]. The balance may shift as the importance of green issues, and the consequences of ignoring them, increase. However, disseminating the true picture of true green will likely have to transcend traditional media channels [11]. According to William et al. [11], most green social networks specialize, but that may be an artifact of their relative immaturity. A few green social network sites have grown to the point of being truly comprehensive.

Considering that the use of social media for green initiatives can have many positive benefits $[13,14$, $44,45]$, such as to extend and build your green brand by let partners, prospects, and customers get to know the person and professional personality behind your green company. In recent years, the rapid development of Internet, Internet of Things, and Cloud Computing have led to the explosive growth of data in almost every industry and business area. Big data has rapidly developed into a hot topic that attracts extensive attention from academia, industry, and governments around the world. There are many challenges in harnessing the potential of big data today, ranging from the design of processing systems at the lower layer to analysis means at the higher layer, as well as a series of open problems in scientific research. Big data processing systems suitable for handling a diversity of data types and applications are the key to supporting scientific research of big data [46]. Social networking tools (e.g., Twitter, LinkedIn, Facebook, MySpace) have been proliferating on the internet.

Social media are transforming the way information travels within and between networks of individuals [47]. Although the research on social networks dates back to early 1920s, nevertheless, social media analytics is a nascent field that has emerged after the advent of Web 2.0 in the early 2000s. The key characteristic of the modern social media analytics is its data- centric nature. Social media analytics refer to the analysis of structured and unstructured data from social media channels. Social media is a broad term encompassing a variety of online platforms that allow users to create and exchange content. User-generated content (e.g., sentiments, images, videos, and bookmarks) and the relationships and interactions between the network entities (e.g., people, organizations, and products) are the two sources of information in social media [48].

Social media have profoundly changed our lives and how we interact with one another and the world around us [49, 50]. Recent research indicates that more and more people are using social media applications such as Facebook and Twitters for various reasons such as making new friends, socializing with old friends, receiving information, and entertaining themselves [51-54]. Social media analysis will extract value from vast amount of social media data to detect and discover new knowledge to understand how industry is changing, and use the findings and improved understanding to achieve competitive advantage against their competitors [55, 
56]. Social media competitive analysis allows a business to gain possible business advantage by analyzing the publicly available social media data of a business and its competitors [56]. As social media have become a topic of interest for many industries, it is important to understand how social media data can be harvested for decision-making [56].

With the development of smart devices and cloud computing, more and more public data can be collected from various sources and can be analyzed in an unprecedented way. The huge social and academic impact of such developments caused a worldwide buzz for big data [57]. Data flow is an ordered sequence, which is consecutive, high-speed, infinite and time varying. It's also of great importance in internet management, internet security and internet experiment. However, with the rapid development of internet technology, the number of internet applications and users keeps rising, and the internet data is growing exponentially [24]. There are stricter requirements about the efficiency, expandability and stability of the data flow in social media.

\section{Green initiative opportunity}

The main opportunities associated green initiative of libraries using social media are seen to be related to its low cost. At the same time, its ability to take the library service to users in their preferred spaces, the opportunity to build a sense of green community between the library and its users, to support codevelopment of collections and help keep librarians updated on industry news and initiatives[15]. Challenges are the considerable time that is required to maintain an active social media presence, the pressure to respond instantly to service queries, the variability of skills across library staff for using social media effectively, striking the right tone between professional and personal, coordinating activities across the institution to avoid duplication, maintaining visibility for the library brand and copyright issues relating to hosting library resources on social media sites. Small steps in going green can have a big impact for the library's image. The core of a green library is to be seen to be making reliable environmental information easily accessible.

In this era of big data science, it is critical for organizations and businesses to be able to embrace this new facility and to accurately integrate the knowledge-bases from multiple sources into the organizational information repository that allow green initiative. The availability of a mechanism that allows seamless consolidation of knowledge from external sources will enrich the capability of the organization to make accurate decision-making for green technology. These heterogeneous external sources are growing very significantly in the last few years, especially due to the availability of wireless and mobile technologies, crowd-sourcing facilities, Internet of Things and sensor networks, as well as social media and web data. All these technologies generate huge amount of data and together they can be extracted to generate values to the organization and to establish situational awareness of the community or market trends.

\subsection{Social media initiative}

The main opportunities associated green initiative of libraries using social media are seen to be related to its low cost. At the same time, its ability to take the library service to users in their preferred spaces, the opportunity to build a sense of green community between the library and its users, to support codevelopment of collections and help keep librarians updated on industry news and initiatives. Challenges are the considerable time that is required to maintain an active social media presence, the pressure to respond instantly to service queries, the variability of skills across library staff for using social media effectively, striking the right tone between professional and personal, coordinating activities across the institution to avoid duplication, maintaining visibility for the library brand and copyright issues relating to hosting library resources on social media sites.

There are many options and degrees to which a company can differentiate itself as a good green, sustainable citizen; and, there are many constructive contributions that could be made by social media to get the green messages out with the desired result [11].The strategy of going "green" represents a somewhat moving target. Sustainability varies widely depending upon the product lifecycle stage being analyzed, as well as indirect effects from the supply chain $[16,17]$.

Many libraries are reluctant to adopt green innovation strategies unless there are clear cost benefits from doing so because such short term investments for long term returns are considered risky in corporate environments where performance is judged and based on short-term quarterly returns.

However, for the adventurous, a holistic integration of green into entire product lifecycle is worth tackling because of the growth potential it offers [18]. Currently there is limited differentiation in how social media channels are used to promote green technology. Similar objectives and tactics apply across all social media tools, but it is envisaged that this will change rapidly with strategies becoming increasingly channel-specific.

Social media can provide many useful benefits to the individual or organization growing and evolving its sustainable green identity and actions. In a positive, supportive spirit of sustainability and green initiatives, the following ideas are offered to ensure that the use of social media is increasingly successful 
and useful, in that, it contributes to strategic innovation and management including planning, implementation, and control [13]. Social media can be used for green companies by giving the value to the consumer in the comparison of products and services [14].

\section{Library in Social Media Perspective}

Most libraries think they do not have any role in social networking [26]. However, study by $\mathrm{Chu}$ and Nalani-Meulemans [27] and Charnigo and BarnettEllis [28] showed that social media help librarians to stay connected with the users. Recently, Kai-Wah and Du [29] showed how the use of social media by library has now become mainstream. For example, in Asia, North America and Europe, $71 \%$ were found to be using social media tools with a further $13 \%$ saying they planned to use them. Facebook and Twitter were the most commonly used tools. Study by Ayu and Abrizah[30] showed the employs content analysis to examine current uses of the library Facebook page. A checkpoint was developed to analyze the libraries' usage and application of Facebook page. The authors explores the use and application of Facebook among Malaysian academic libraries in order to provide academic libraries with ideas for best practices in using social networking sites to better profile themselves and communicate effectively with their users.

Tyler [31] discussed the increasing interest in social media, the marketing project officers were keen to explore how they could be used by librarians and library services. But they did not wish to embark on campaigns which use social media if library staff and users are unable to access them. Based on this study, evidence suggested that many librarians were prevented from accessing social media tools in a work setting, and that access varied across the different library sectors.

Study by Zhoorian-Fooladi [32] showed that the librarians use social media to promote library services, manage organizational knowledge and receiving instant feedback from users. Workflow obstacles, technology obstacles, organizational obstacles and personal obstacles deter librarians from participating in social media.

Table 2. Social media usage in library

\begin{tabular}{|c|c|c|c|c|}
\hline Authers. & Serroes. & Nefacting & Mictering & Greeti Litary \\
\hline Znocian-Fcelsdi [32] & 1 & & 1 & $x$ \\
\hline Ther [3:] & & & 1 & $x$ \\
\hline Bublasdi [33] & & $T$ & & $x$ \\
\hline Chamiso \& Beract.Ellis [2S] & & & & $x$ \\
\hline Clm $\alpha$ Xahm-Mruketsens [27] & & 1 & & $x$ \\
\hline 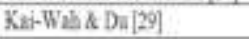 & & l & & $x$ \\
\hline
\end{tabular}

Many libraries are already experimenting with different social media services like Twitter or
Facebook to interact and connect with their patrons, yet there are still a number of questions that come up as this is still fairly new territory [33].

\section{Green Library Initiative}

Libraries are particularly responsible not only for disseminating information on environmental sustainability but also for serving as examples to follow. Small steps in going green can have a big impact on the library's image [34]. According to Hauke and Werner [34], ecological sustainability which can often be an undervalued aspect for the marketing strategy of the library, has more impact on clients and on stakeholders than one might expect. Enthusiastic library users are calling on libraries not just to provide popular services but to communicate a clear green identity. Although "Green marketing" today leads to $1,100,000$ Google hints, a "green" library image as a marketing tool, or "green" library marketing strategies seem expressis verbis never to be described nor discussed in the LIS literature.

A public library may be part of a network of the municipalities: the library can highlight the municipality's green profile and this could be a good marketing strategy [34]. The creation of green libraries is approaching a tipping point, generating a Green Library Movement, which is comprised of librarians, libraries, cities, towns, college and university campuses committed to greening libraries and reducing their environmental impact [35]. The amount of information available on green libraries and green library practices is limited but continues to grow. Libraries are trusted community institutions, which makes them ideal locations for green technology demonstrations and strategically positions them to become community models for sustainability [36].

There are many options and degrees to which a company can differentiate itself as a good green, sustainable citizen; and, there are many constructive contributions that could be made by social media to get the green messages out with the desired result [11]. The strategy of going "green" represents a somewhat moving target. Sustainability varies widely depending upon the product lifecycle stage being analyzed, as well as indirect effects from the supply chain [17, 37]. For example, greenwashing has become common in recent years, primarily due to a lack of regulation, oversight, and monitoring of green marketing claims [38, 39]. Many libraries are reluctant to adopt green innovation strategies unless there are clear cost benefits from doing so because such short term investments for long term returns are considered risky in corporate environments where performance is judged and based on short-term quarterly returns. However, for the adventurous, a holistic integration of green into entire product lifecycle is worth tackling because of the growth 
potential it offers. Designing a business model around the needs of the environment, instead of retrofitting existing models to be more eco-friendly, is radically innovative, and holds the promise of both industry leadership, consumer goodwill, and premium pricing $[18,40]$. These corporations use green innovation strategies as a competitive advantage and are the most likely to receive government support for their efforts [41]. The opportunity is matched by the risk. However, such models are strategically imbalanced, compromising productivity in favor of the environment, and may not be viable in the longer-term [42].

Although many libraries already have a daily green routine, such as recycling, double-sided copies, switching the lights off when not needed etc, most don't venture beyond these basics. There are a lot of examples as to how libraries can handle such issues in a user-friendly way, and how they go about marketing their respective efforts [34].

\section{Conclusion}

The study will improve library productivity to promote library services and practices. Such services and practice will bring values to promote trustworthiness between libraries, users and industry contract. The research will improve the ability of well-informed relationship between libraries and users to exercise their democratic rights and to play an active role in society. At the same time, the research will limit distinct from the practical role of sharing resources in that libraries provide a physical place for teachers and learners to meet and collaborate with build a sense of community that can enhance teaching and learning process with other institutions.

Social media has the potential to facilitate much closer relationship between libraries and their users. Social media is reasonably well embedded in library and its moving towards a central role in how libraries are communicating with their end users. At the same time, its ability to take the library service to users in their preferred spaces, the opportunity to build a sense of community between the library and its users, to support co-development of collections and help keep librarians updated on industry news and initiatives. Social Media is important ingredient to help library to transform a part of human knowledge that can enhance human knowledge by using particular knowledge technology from social media.

This technology will improve performance in dealing with the library environment, work performance and efficient service delivery for more competitive and productive economy that can help create sustainable communities. Therefore, having an ability to analyse information from social media in a timely fashion can ensure libraries have a competitive edge to improve productivity in relation to develop teaching and learning environment.

\section{References}

[1] T. A. T. Izhar, T. Torabi, M. I. Bhatti, and F. Liu, "Recent developments in the organization goals conformance using ontology," Expert Systems with Applications, vol. 40, pp. 4252-4267, 2013.

[2] M. Berber, E. Graupner, and A. Maedche, "The information panopticon in the big data era," Journal of Organization Design, vol. 3, pp. 14-19, 2014.

[3] J. O. e. Sá, C. Martins, and P. Simões, "Big Data in Cloud: A Data Architecture," New Contributions in Information Systems and Technologies, vol. 353, pp. 723$732,2015$.

[4] J. Kang and K. M. Sim, "Ontology and search engine for cloud computing system," presented at the IEEE 2011 International Conference on System Science and Engineering (ICSSE), 2011.

[5] J. R. Galbraith, "Organization design challengers resulting from big data," Journal of Organization Design, vol. 3, pp. 2-13, 2014.

[6] B. T. Hazen, C. A. Boone, J. D. Ezell, and L. A. JonesFarmer, "Data quality for data science, predictive analytics and big data in supply chain management: An introduction to the problem and suggestions for research and application," International Journal Production Economics, vol. 154, pp. 72-80, 2014.

[7] R. L. Grossman and K. P. Siegel, "Organizational models for big data and analytics, "Journal of Organization Design, vol. 3, pp. 20-25, 2014.

[8] T. H. Davenport and J. Dyche, "Big data in big companies," International Institute for Analytics2013.

[9] J. Manyika, M. Chui, B. Brown, J. Bughin, R. Dobbs, C. Roxburgh, et al. (2011). Big data: The next frontier for innovation, competition and productivity.Available: http://www.mckinsey.com/insights/business_technology/ big_data_the_next_frontier_for_innovation

[10] N. Hultman, K. Sierra, and A. Shapiro. (2012, 17 March). Innovation and Technology for Green Growth. Available: http://www.brookings.edu/ /media/research/ files/reports/2012/10/blum-roundtable/10-green-growthhultman-sierra.pdf

[11] K. C. Williams, R. A. Page, and A. R. Petrosky, "Green Sustainability and New Social Media," vol. 9, pp. 11-13, 2014.

[12] C. P. M. Sianipar, R. C. Putri, and D. Wibisono, "Social Media Analysis in Performance Measurement:Moving Toward a New Approach," in The 3rd International Conference on Technology and Operations Management, Bandung, Indonesia, 2012, pp. 715-721. 
[13] R. Matthews. (2011, 15 March). 50 best blogs for green business students. Available:http://www.thegreenmarketoracle.com/2011/03/50-best-blogs-for-greenbusiness.html

[14] R. Matthews. (2011, 15 March). Social media marketing and environmental sustainability. Available: http://www.thegreenmarketoracle.com/2011/02/socialmedia-marketing-and.html

[15] V. Cornell, "Greening the library: Collection development decisions," The Journal of New Members Round Table, vol. 1, pp. 1-15, 2010.

[16] H. Ny, MacDonald, J.P., G. Broman, R. Yamamoto, and K. H. Robert, "Sustainability Constraints as System Boundaries: An Approach to Making Life-Cycle Management Strategic," Journal of Industrial Ecology, vol. 10, pp. $61-77,2006$

[17] S. K. Sikdar, P. Glavic, and R. Jain, Technological Choices for Sustainability. New York: Springer, 2004.

[18] J. M. Ginsberg and P. Bloom, "Choosing the Right Green Marketing Strategy," MIT Sloan Management Review, vol. 4, pp. 77-84, 2004.

[19] T. H. Davenport, "Information management and big data- Reference architecture," Oracle, California, USA2014.

[20] S. Lohr. (2012, 15 September 2015). How big data became so big. Available:http://www.nytimes.com/2012/ 08/12/business/how-big-data-became-so-bigunboxed.html?_r=0

[21] H. Chen, R. H. L. Chiang, and V. C. Storey, "Business intelligence and analytics: from big data to big impact," MIS Quarterly, vol. 36, pp. 1165-1188, 2012.

[22] R. K. Perrons and J. W. Jensen, "Data as an asset: Why the oil and gas sector can learn from other industries about "Big Data"," Energy Policy, vol. 81, pp. 117-121, 2015 .

[23] I. Polato, R. Re, A. Goldman, and F. Kon, "A comprehensive view of Hadoop research- A systematic literature review," Journal of Networking and Computer Application vol. 46, pp. 1-25, 2014.

[24] Q. Zhi, L. Zhao-Wen, and M. Yan, "Research of Hadoop-based data flow management system," The Journal of China Universities of Post and Telecommunications, vol. 18, pp. 164-168, 2011.

[25] C. Esposito, M. Ficco, F. Palmieri, and A Castiglione, "A knowledge-based platform for big data analytics based on publish/subscribe services and stream processing," Knowledge-Based Systems, vol. 79, pp. 3-17, 2015.

[26] C. D. Rosa, J. Cantrell, and A. Havens, "Sharing, privacy and trust in our networked world: A report to the OCLC membership," Dublin2007.
[27] M. Chu and Y. Nalani-Meulemans, "The problems and potential of MySpace and Facebook usage in academic libraries," Internet Reference Services Quarterly vol. 13, pp. 69-85, 2008.

[28] L. Charnigo and P. Barnett-Ellis, "Checking out Facebook.com: The impact of a digital trend on academic libraries," Information Technology and Libraries vol. 26, pp. 23-34, 2007.

[29] S. Kai-Wah C and H. S. Du, "Social Networking Tools for Academic Libraries," Journal of Librarianship and Information Science, vol. 45, pp. 64-75, 2012.

[30] A. R. Ayu and A. Abrizah, "Do you Facebook? Usage and applications of Facebook page among academic libraries in Malaysia," The International Information \& Library Review, vol. 43, pp. 239-249, 2011.

[31] A. Tyler. (2012) Welsh Libraries and Social Media: A Survey. Ariadne. Available:http://www.ariadne.ac.uk/ issue68/tyler

[32] N. Zhoorian-Fooladi, "Academic librarians and their social media presence: a story of motivations and deterrents," Information Development, vol. 30, pp. 159$171,2014$.

[33] A. Burkhardt, "Social Media: A guide for college and university libraries," College and Research Libraries News, vol. 70, pp. 10-24, 2010.

[34] P. Hauke, K. Latimer, and K. U. Werner. (2013). The Green Library: The challange of environmental sustainability. Available:http://edoc.hu-berlin.de/miscellanies/greenlibrary-2062/379/PDF/379.pdf

[35]M. Antonelli, "The Green Library Movement: An Overview and Beyond," Elecronic Green Journal, vol. 1, pp. 1-11, 2008

[36] Laura L. Barnes. (2012, 17 March). Green Buildings as Sustainability Education Tools. Available: https://www.ideals.illinois.edu/bitstream/handle/2142/3413 8/Green\%20Buildings\%20as\%20Sustainability\%20Educat ion $\% 20$ Tools $\% 20$ deposit $\% 20$ version.pdf?sequence $=2$

[37] H. Ny, J. P. MacDonald, G. Broman, R. Yamamoto, and K.-H. Robert, "Sustainability constraints as system boundaries: An approach to making life-cycle management strategic," Journal of Industrial Ecology, vol. 10, pp. 6177, 2006.

[38] R. Dahl, "Green washing: Do you know what you're buying?," Environmental Health Perspectives, vol. 118, pp. A246-A252, 2010.

[39] C. A. Ramus and I. Montiel, "When are corporate environmental policies a form of greenwashing?," Business Society, vol. 44, pp. 377-414, 2005.

[40] C.-S. Chen and L.-Y. Lin. (2011, 17 March). A New Framework: Make Green Marketing Strategy go with Competitive Strategy. Available: http://www.jgbm.org/ page/20\%20Chun-Shuo\%20Chen.pdf 
[41] R. J. Orsato, "Competitive environmental strategies: When does it pay to be green?," California Management Review, vol. 48, pp. 127- 143, 2006.

[42] M. G. Trotta, "Product lifecycle management: Sustainability and knowledge management as keys in a complex system of product development," Journal of Industrial Engineering and Management, vol. 3, pp. 309322,2010 .

[43] J. W. Treem and P. M. Leonardi, "Social Media Use in Organizations: Exploring the Affordances of Visibility, Editability, Persistence, and Association," Communication Yearbook, vol. 36, pp. 143-189, 2012.

[44] W. Newman. (2012, 15 March). Strategic intent for green marketing and disclosure using social media. Available: http://sustainablebusinessforum.com/ williamnewman/57188/strategic-intent-green-marketingand- disclosure-using-social-media

[45] B. Thurston. (2012) The social media road map. Fast Company. 69-80

[46] X. Jin, B. W. Wah, X. Cheng, and Y. Wang, "Significance and challenges of big data research," Big Data Research, vol. 2, pp. 59-64, 2015.

[47] H. Gangadharbatla, L. F. Bright, and K. Logan, "Social media and news gathering: tapping into the millennial mindset," The Journal of Social Media in Society, vol. 3, pp. 45-63, 2014.

[48] A. Gandomi and M. Haider, "Beyond the hype: Big data concepts, methods and anlytics," International Journal of Information Management, vol. 35, pp. 137-144, 2015.

[49] E. Qualman, Socialnomics how social media transforms the way we live and do business. Hoboken: Wiley John \& Sons, Inc., 2009.

[50] L. Safko and D. K. Brake, The social media bible: Tactics, tools, and strategies for business success. Hoboken: Wiley John \& Sons, Inc. , 2009.

[51] A. M. Kaplan and M. Haelein, "Users of the worl, united! The challenges and opportunities of Social Media," Business Horizons, vol. 53, pp. 59-68, 2010.

[52] P. H. Keckley. (2010). Social networks in health care: Communication, collaboration and insights. Available: http://www.deloitte.com/ assets/Dcom-UnitedStates/ Local\%20Assets/Documents/US CHS 2010Social Networks 070710.pdf

[53] N. Park, K. F. Kee, and S. Valenzuela, "Being immersed in social networking environment: Facebook groups, uses and gratifications, and social outcomes"CyberPsychology \& Behavior, vol. 12, pp. 729733, 2009.

[54] J. Raacke and J. Bonds-Raacke, "MySpace and Facebook: Applying the uses and gratifications theory to exploring friend-networking sites," CyberPsychology \& Behavior, vol. 11, pp. 169-174, 2008.
[55] G. Governatori and R. Iannella, "A modeling and reasoning framework for social networks policies," Enterprise Information Systems, vol. 5, pp. 145-167, 2011.

[56] W. He, S. Zha, and L. Li, "Social media competitive analysis and text mining: A case study in pizza industry," International Journal of Information Management vol. 33, pp. 464-472, 2013.

[57] T. Huang, L. Lan, X. Fang, P. An, J. Min, and F. Wang, "Promises and challenges of big data computing in health sciences," Big Data Research, vol. 2, pp. 2-11, 2015. 